Int. J. Morphol.,

34(3):975-985, 2016.

\title{
The Rotator Cuff Footprint: A Cadaveric Study of the Morphometry and Morphology
}

\author{
La Huella del Manguito Rotador: Un Estudio en Cadáver de su Morfometría y Morfología
}

\author{
N. Naidoo*; L. Lazarus* \& K. S. Satyapal*
}

NAIDOO, N.; LAZARUS, L. \& SATYAPAL, K. S. The rotator cuff footprint: A cadaveric study of the morphometry and morphology. Int. J. Morphol., 34(3):975-985, 2016.

\begin{abstract}
SUMMARY: The musculotendinous hood of the rotator cuff muscle complex is formed by four tendons which thicken and merge with the underlying glenohumeral capsule as they insert onto the respective regions of the humeral head. This insertional anatomy has been reported to exhibit several pathological patterns which serve as the basis for the operative repair of cuff tears. Since previous literature concentrated on macro-evaluations of tears specific to the supraspinatus tendon, the present study aimed to investigate the macro- morphological and morphometric parameters of all four rotator cuff tendons. Observation of the insertion site configurations and computation of the relative tendon morphometry were performed once the glenohumeral region in forty adult cadaveric specimens $(n=80)$ were bilaterally dissected. Statistical analysis also reflected the demographic representation of the sample: (Age: $74.83 \pm 12.92$ years old; Gender: 24 Males, 16 Females; Race: 38 White, 2 Black). The general mean supero-inferior and medio-lateral distances were recorded specific to the entire rotator cuff and each tendinous insertion site as follows: i) Subscapularis: $22.57 \pm 3.13 \mathrm{~mm}, 20.45 \pm 4.79$ $\mathrm{mm}$; ii) Supraspinatus: $15.20 \pm 4.29 \mathrm{~mm}, 20.14 \pm 5.38 \mathrm{~mm}$; iii) Infraspinatus: $19.49 \pm 5.21 \mathrm{~mm}, 19.07 \pm 4.74 \mathrm{~mm}$; iv) Teres minor: $19.02 \pm 5.21$ $\mathrm{mm}, 15.33 \pm 3.75 \mathrm{~mm}$; v) Entire rotator cuff: $76.28 \pm 10.57 \mathrm{~mm}, 75.18 \pm 11.41 \mathrm{~mm}$. Although variation in insertion configurations existed, predominant shapes were identified: Subscapularis - Oval (72.5\%), Supraspinatus - Rectangular (76.3 \%), Infraspinatus - Oval (78.8 $\%)$, Teres minor - Round (100\%). In view of the statistically significant P values, it may be postulated that knowledge of the superoinferior and medio-lateral distances may provide dimensional data required to obtain optimal cuff coverage during reconstruction procedures. Furthermore, the variation in the insertion patterns may indicate the progression of rotator tendon tears.
\end{abstract}

KEY WORDS: Rotator cuff; Footprint; Insertion; Morphology; Morphometry.

\section{INTRODUCTION}

Knowledge of the rotator cuff footprint has long been deemed beneficial, especially to the orthopaedic surgeon for the repair and restoration of torn rotator cuff tendons to their functional anatomic positions (Dugas et al., 2002; Curtis et $a l ., 2006)$. Despite its role as the ultimate dynamic stabilizer of the shoulder, the aetiological component of abnormalities encountered within and around the rotator cuff muscle complex remains an area of much question (Armfield et al., 2003; Jurch, 2009; Schaeffeler et al., 2011; Stoppino et al., 2013). Rotator cuff disease is thus the result of the combined interaction between intrinsic (vascularity, age) and extrinsic (mechanical, anatomical) factors (Schaeffeler et al.,; Stoppino et al.,).

The rotator cuff muscle complex appears as a musculotendinous hood, occupying the region between the coracoacromial arch and the humeral head (Standring et al.,
2008; Jurch). It is created by the fusion of the tendons of four muscles, viz. subscapularis, supraspinatus, infraspinatus and teres minor, with the fibrous capsule of the shoulder joint (Standring et al.,). Although these four scapulo-humeral muscles appear as distinct structures superficially, in the deeper regions, their tendons fuse with each other and the fibrous capsule of the shoulder joint to create the characteristic appearance of the cuff (Rockwood et al., 2004). The subscapularis muscle classically arises from the anterior part of the scapula and inserts onto the lesser tuberosity of the humerus (Rockwood et al., 2004; Sinnatamby, 2006; Standring et al.,; Muscolino, 2010). The supraspinatus, infraspinatus and teres minor muscles all originate from the posterior scapular region to insert onto the superior, posterior and inferior facets of the greater humeral tuberosity, respectively (Rockwood et al.,; Sinnatamby, 2006; Standring et al., 2008; Muscolino, 2010). 
Since rotator cuff disease exhibits several different pathological patterns arising from the composite horseshoe-shaped rotator cuff footprint, the insertional anatomy of the rotator cuff muscle complex presents as the basis for the operative repair of rotator cuff tears (Curtis et al.,; Schaeffeler et al.,) (Figure 1). Although previous studies have documented the morphology and morphometry of the insertional region of certain rotator cuff tendons, the rotator cuff footprint along with all four tendons have not been evaluated as a complete anatomical unit (Dugas et al.,; Curtis et al.,; Mochizuki et al., 2009; Cadet et al., 2010; Martin Martin et al., 2012; Stoppino et al.,). Furthermore, the literature has focused chiefly on the macro-evaluations of the repair of torn tendons and tears specific to the supraspinatus tendon (Dugas et al.,; Curtis et al.,; Mochizuki et al.,; Cadet et al.,; Martin Martin et al.,; Stoppino et al.,).

Accordingly, the aim of this study was to investigate the shape and morphometric parameters of the insertional sites of the rotator cuff tendons.

\section{MATERIAL AND METHOD}

Bilateral dissection, employing both anterior and posterior approaches of the glenohumeral region in forty adult cadaveric specimens $(n=80)$ was conducted in accordance with the ethical standards of the institution's ethics council (Ethical Clearance Approval Number: BE279/15).

The sample comprised of 24 Males and 16 Females with a mean age of $74.83 \pm 12.92$ years old (Range: 54-94 years' old). With regard to the racial distribution, there were 38 White and 2 Black individuals.

Once the proximal humerus and the adjoining rotator cuff muscle-tendon complex were isolated, the four individual muscles were dissected in the mediolateral direction along three intervals, viz. subscapularis and supraspinatus, supraspinatus and infraspinatus, infraspinatus and teres minor. The supero-inferior (length) and medio-lateral (width) distances of the complete rotator cuff, i.e. the characteristic horseshoe-shape extension, and the individual tendinous insertional sites were recorded. The extent of the infraspinatus tendon as it protrudes anteriorly was measured and documented. Thereafter, each tendon was dissected free from its attachment to the proximal humerus and the shape of its insertional site was then observed.

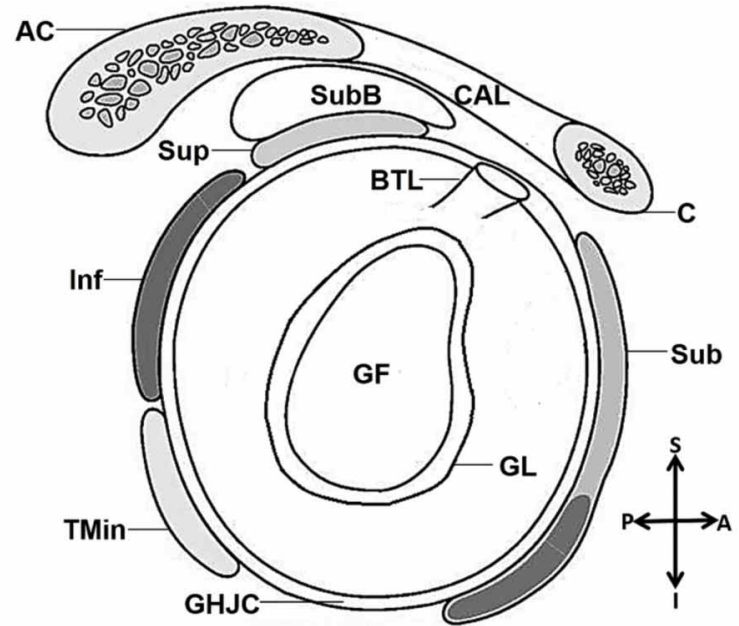

Fig. 1. Lateral view of the characteristic horseshoe-shaped rotator cuff footprint (Adapted from http://www.fotosearch.com/LIF114/ sa301050/, accessed on 23 February 2016).

A. Anterior; AC. Acromion; BTL.Long head of Biceps brachii tendon; C. Coracoid process; CAL. Coracoacromial ligament; GF. Glenoid fossa; GL. Glenoid labrum; GHJC. Glenohumeral joint capsule; I. Inferior; Inf. Infraspinatus; P. Posterior; S. Superior; Sub. Subscapularis; SubB. Subacromial bursa; Sup. Supraspinatus; TMin.Teres minor.

All macroscopic measurements were done through the use of a digital calliper (Mitutoyo Digimatic Caliper, Model No. CD-8" C) and were measured three times by the same investigator in an attempt to reduce intra-observer error.

The statistical analysis was performed using the IBM Statistical Package for Social Sciences (SPSS Inc., Chicago, Illinois, USA), version 21.0. The means and frequencies of the continuous and categorical variables, respectively, were compared for difference and/or equivalence between parameters and demographically-relevant population factors. Levels of significance revealing $P$ values less than 0.05 were considered to be statistically significant.

\section{RESULTS}

Morphometric Parameters: Supero-inferior and Medio-lateral distances of the Tendinous Insertional Sites: The general analysis of the mean morphometric parameters pertaining to the rotator cuff and its relative tendons computed the following results (Table I):

Supero-inferior distances of:

i) Subscapularis tendon insertion/footprint: $22.57 \pm 3.13 \mathrm{~mm}$. ii) Supraspinatus tendon insertion/footprint: $15.20 \pm 4.29 \mathrm{~mm}$. 
iii) Infraspinatus tendon insertion/footprint: $19.49 \pm 5.21 \mathrm{~mm}$.

iv) Teres minor tendon insertion/footprint: $19.02 \pm 5.21 \mathrm{~mm}$.

v) Entire rotator cuff insertion/footprint: $76.28 \pm 10.57 \mathrm{~mm}$.

Medio-lateral distances of:

i) Subscapularis tendon insertion/footprint: $20.45 \pm 4.79 \mathrm{~mm}$.

ii) Supraspinatus tendon insertion/footprint: $20.14 \pm 5.38 \mathrm{~mm}$.

iii) Infraspinatus tendon insertion/footprint: $19.07 \pm 4.74 \mathrm{~mm}$.

iv) Teres minor tendon insertion/footprint: $15.33 \pm 3.75 \mathrm{~mm}$.

v) Entire rotator cuff insertion/footprint: $75.18 \pm 11.41 \mathrm{~mm}$.

Each morphometric parameter was recorded in accordance with right and left sides (Table I).

Supero-inferior distances of:

i) Subscapularis tendon insertion/footprint:

Left $=21.54 \pm 4.08 \mathrm{~mm}$; Right $=23.52 \pm 3.81 \mathrm{~mm}$.

ii) Supraspinatus tendon insertion/footprint:

Left $=14.14 \pm 4.37 \mathrm{~mm}$; Right $=16.26 \pm 3.98 \mathrm{~mm}$.

iii) Infraspinatus tendon insertion/footprint:

Left $=19.84 \pm 5.78 \mathrm{~mm} ;$ Right $=19.13 \pm 5.07 \mathrm{~mm}$.

iv) Teres minor tendon insertion/footprint:

Left $=18.88 \pm 5.24 \mathrm{~mm} ;$ Right $=19.18 \pm 5.23 \mathrm{~mm}$.

v) Entire rotator cuff insertion/footprint:

Left $=74.40 \pm 11.43 \mathrm{~mm} ;$ Right $=78.15 \pm 9.40 \mathrm{~mm}$

The comparison of the supero-inferior distance of the supraspinatus tendon insertion/footprint between left and right sides yielded a statistically significant $P$ value of 0.026 (Table I).

Medio-lateral distances of:

i) Subscapularis tendon insertion/footprint: Left $=21.02 \pm 4.63 \mathrm{~mm}$; Right $=19.88 \pm 4.94 \mathrm{~mm}$.

ii) Supraspinatus tendon insertion/footprint: Left $=19.69 \pm 5.02 \mathrm{~mm} ;$ Right $=20.60 \pm 5.75 \mathrm{~mm}$.

iii) Infraspinatus tendon insertion/footprint:

Left $=18.92 \pm 4.86 \mathrm{~mm} ;$ Right $=19.22 \pm 4.68 \mathrm{~mm}$.

iv) Teres minor tendon insertion/footprint:

Left $=15.22 \pm 3.74 \mathrm{~mm}$; Right $=15.44 \pm 3.79 \mathrm{~mm}$.

v) Entire rotator cuff insertion/footprint:

Left $=75.49 \pm 11.81 \mathrm{~mm} ;$ Right $=74.87 \pm 11.15 \mathrm{~mm}$.

The morphometric parameters were also investigated from a demographic perspective by considering the sex and racial distribution of the sample.

The mean supero-inferior and medio-lateral distances in male and female individuals are reflected below (Table I).
Supero-inferior distance of:

i) Subscapularis tendon insertion/footprint:

Male $=22.66 \pm 4.41 \mathrm{~mm} ;$ Female $=22.32 \pm 3.91 \mathrm{~mm}$.

ii) Supraspinatus tendon insertion/footprint:

Male $=15.01 \pm 4.30 \mathrm{~mm} ;$ Female $=15.48 \pm 4.32 \mathrm{~mm}$.

iii) Infraspinatus tendon insertion/footprint:

Male $=19.75 \pm 5.28 \mathrm{~mm} ;$ Female $=19.09 \pm 5.67 \mathrm{~mm}$.

iv) Teres minor tendon insertion/footprint:

Male $=20.16 \pm 5.60 \mathrm{~mm}$, Female $=17.33 \pm 4.06 \mathrm{~mm}$.

v) Entire rotator cuff insertion/footprint:

Male $=77.58 \pm 10.68 \mathrm{~mm} ;$ Female $=74.31 \pm 10.24 \mathrm{~mm}$.

A statistically significant $\mathrm{P}$ value of 0.016 was recorded for the comparison of the supero-inferior distance of the teres minor tendon insertion/footprint between male and female individuals (Table I).

Medio-lateral distance of:

i) Subscapularis tendon insertion/footprint:

Male $=20.82 \pm 4.36 \mathrm{~mm}$; Female $=19.90 \pm 5.40 \mathrm{~mm}$.

ii) Supraspinatus tendon insertion/footprint:

Male $=21.05 \pm 5.75 \mathrm{~mm} ;$ Female $=18.78 \pm 4.52 \mathrm{~mm}$.

iii) Infraspinatus tendon insertion/footprint:

Male $=19.61 \pm 4.44 \mathrm{~mm} ;$ Female $=18.26 \pm 5.13 \mathrm{~mm}$.

iv) Teres minor tendon insertion/footprint:

Male $=15.82 \pm 3.72 \mathrm{~mm}$; Female $=14.60 \pm 3.73 \mathrm{~mm}$.

v) Entire rotator cuff insertion/footprint:

Male $=77.59 \pm 10.93 \mathrm{~mm} ;$ Female $=71.56 \pm 11.33 \mathrm{~mm}$

The comparison of the medio-lateral distance of the entire rotator cuff insertion/footprint in between male and female individuals yielded a statistically significant $P$ value of 0.020 (Table I).

The following mean distances were noted in White and Black individuals of the sample (Table I):

Supero-inferior distance of:

i) Subscapularis tendon insertion/footprint:

White $=22.66 \pm 3.74 \mathrm{~mm}$; Black $=19.37 \pm 2.35 \mathrm{~mm}$.

ii) Supraspinatus tendon insertion/footprint:

White $=15.31 \pm 4.27 \mathrm{~mm}$; Black $=10.85 \pm 3.46 \mathrm{~mm}$.

iii) Infraspinatus tendon insertion/footprint:

White $=19.63 \pm 5.38 \mathrm{~mm}$; Black $=13.69 \pm 3.94 \mathrm{~mm}$.

iv) Teres minor tendon insertion/footprint:

White $=19.02 \pm 5.25 \mathrm{~mm}$; Black $=19.15 \pm 4.08 \mathrm{~mm}$.

v) Entire rotator cuff insertion/footprint:

White $=76.62 \pm 10.36 \mathrm{~mm}$; Black $=63.05 \pm 13.82 \mathrm{~mm}$.

Medio-lateral distance of: 


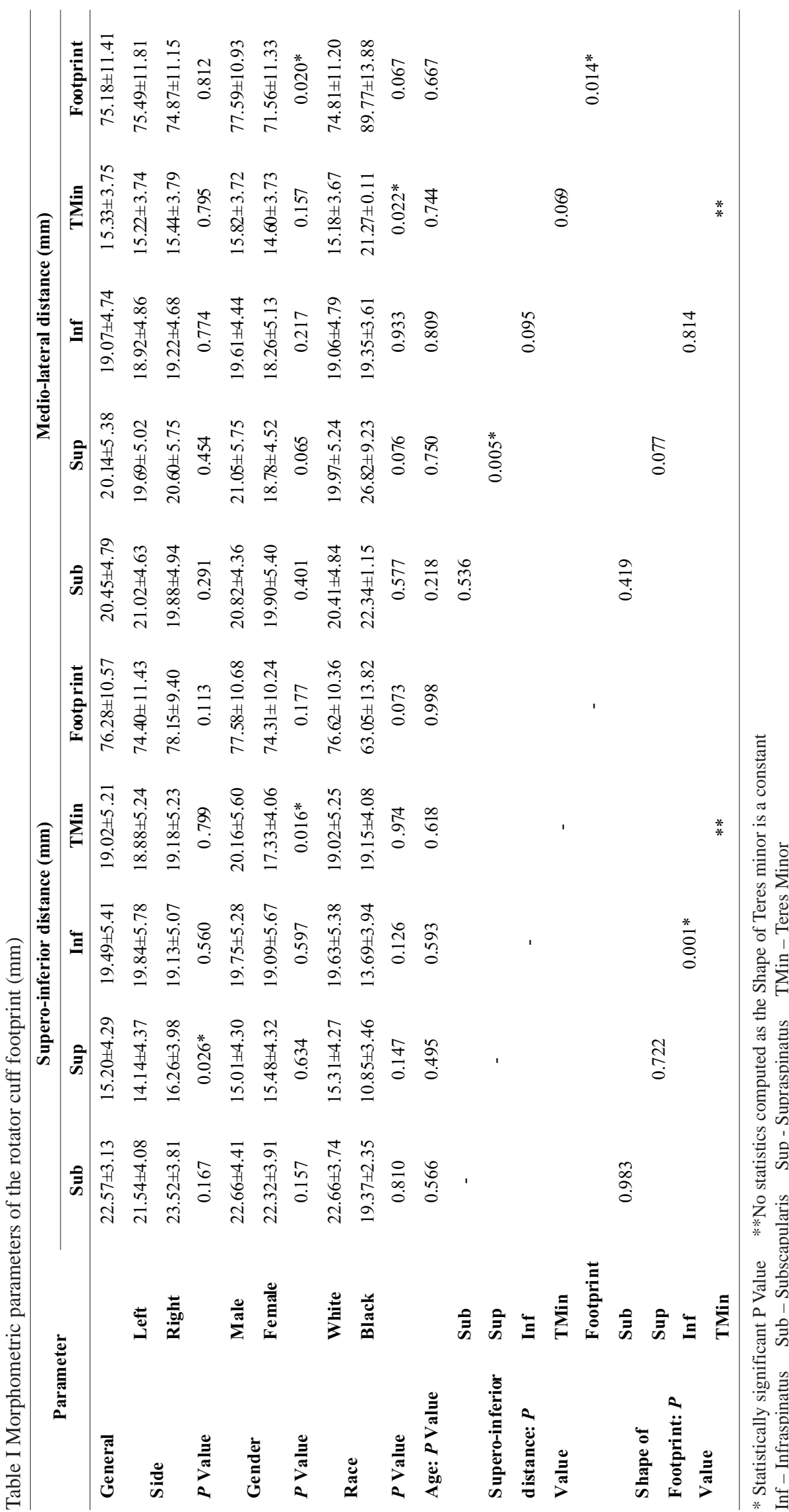

i) Subscapularis tendon insertion/ footprint:

White $=20.41 \pm 4.84 \mathrm{~mm}$;

Black $=22.34 \pm 1.15 \mathrm{~mm}$.

ii) Supraspinatus tendon insertion/ footprint:

White $=19.97 \pm 5.24 \mathrm{~mm}$;

Black $=26.82 \pm 9.23 \mathrm{~mm}$.

iii) Infraspinatus tendon insertion/ footprint:

White $=19.06 \pm 4.79 \mathrm{~mm}$;

Black $=19.35 \pm 3.61 \mathrm{~mm}$.

iv) Teres minor tendon insertion/ footprint:

White $=15.18 \pm 3.67 \mathrm{~mm}$;

Black $=21.27 \pm 0.11 \mathrm{~mm}$.

v) Entire rotator cuff insertion/ footprint:

White $=74.81 \pm 11.20 \mathrm{~mm}$;

Black $=89.77 \pm 13.88 \mathrm{~mm}$.

A statistically significant $P$ value of 0.022 was recorded for the comparison of the medio-lateral distance of the teres minor tendon insertion/footprint between White and Black individuals (Table I).

The morphometric parameters of each tendinous insertional site were further compared with each other and with shape of the insertional site. The correlation of the supero-inferior distance of the supraspinatus tendon insertion/footprint and the entire rotator cuff insertion/ footprint with their relative mediolateral distances yielded statistically significant $P$ values of 0.005 and 0.014 , respectively (Table I). In addition, a $\mathrm{P}$ value of 0.001 , reflective of statistical significance was recorded for the comparison of the shape and the supero-inferior distance of the infraspinatus tendon insertion/ footprint (Table I).

\section{Shape of the Insertional Sites}

Upon analysis of the morphological parameters 
regarding the insertional site of the relative rotator cuff tendons, the subsequent general shapes were deduced (Table II):

i) Subscapularis:

Oval (72.5\%); Triangular (27.5\%) (Figure 2A-B)

ii) Supraspinatus:

Rectangular (76.3\%); Round (23.8 \%) (Figure 3A-B)

iii) Infraspinatus:

Oval (78.8\%); Triangular (21.3\%) (Figure 4A-B)

iv) Teres minor: Round (100\%) (Figure 5)

The incidence of the shapes relating to the insertional site of each rotator cuff tendon in both left and right glenohumeral regions was identified (Table II).

i) Subscapularis:

Left Oval (30\%); Triangular (20\%);

Right - Oval (42.5\%); Triangular (7.5\%)

ii) Supraspinatus:

Left - Rectangular (37.5\%); Round (12.5\%);

Right - Rectangular (38.75\%); Round (11.25\%)

iii) Infraspinatus:

Left - Oval (40\%); Triangular (10\%);

Right - Oval (38.75\%); Triangular (11.25\%)

iv) Teres minor:

Left - Round (50\%);

Right - Round (50\%)

Although the shapes were not always congruent on the right and left sides, a statistically significant $\mathrm{P}$ value of 0.012 was recorded for the comparison between sides and the shape of the footprint of the subscapularis tendon (Table II).

The incidence of shape pertaining to the demographic representation of the sample was recorded accordingly.

In male and female individuals, the incidence of the relative shapes of the insertional site of each rotator cuff tendon is reflected below (Table II).

i) Subscapularis:

Male - Oval (43.75\%); Triangular (16.25\%);

Female - Oval (28.75\%); Triangular (11.25\%)

ii) Supraspinatus:

Male - Rectangular (48.75\%); Round (11.25\%);

Female - Rectangular (27.5\%); Round (12.5\%)

iii) Infraspinatus:

Male - Oval (48.75\%);

Triangular (11.25\%);

Female - Oval (30\%); Triangular (10\%)

iv) Teres minor:
Male - Round (60\%);

Female - Round (40\%)

White and Black individuals presented with the following incidence of shapes regarding the tendinous insertion sites (Table II).

i) Subscapularis:

White - Oval (70\%); Triangular (27.5\%);

Black - Oval (2.5\%); Triangular (0 \%)

ii) Supraspinatus:

White - Rectangular (73.75 \%); Round (23.75\%);

Black - Rectangular (2.5\%); Round (0 \%)

iii) Infraspinatus:

White - Oval (76.25\%); Triangular (21.25\%);

Black - Oval (2.5\%); Triangular (0\%)

iv) Teres minor:

White - Round (97.5\%);

Black - Round (2.5\%)

The comparison of the age with the shape of the footprint of the infraspinatus tendon yielded a statistically significant $\mathrm{P}$ value of 0.033 (Table II).

\section{Anterior Extent of Infraspinatus Tendon}

The present study also observed and documented the extent to which the infraspinatus tendon passed anteriorly from its classical posterior insertion site on the greater humeral tuberosity (Table III). A general value of $10.22 \pm 3.93 \mathrm{~mm}$ was recorded for the anterior extent of the infraspinatus tendon.

The anterior extent of the infraspinatus tendon was found to be $9.97 \pm 3.47 \mathrm{~mm}$ and $10.48 \pm 4.36 \mathrm{~mm}$ on the left and right sides, respectively (Table III).

In male individuals the infraspinatus tendon was seen to extend approximately $10.44 \pm 3.36 \mathrm{~mm}$ anteriorly with female individuals presenting with an anterior extent of $9.90 \pm 4.69 \mathrm{~mm}$ (Table III).

The estimated anterior extent of the infraspinatus tendon in White and Black individuals was $10.28 \pm 3.96 \mathrm{~mm}$ and $8.23 \pm 1.90 \mathrm{~mm}$, respectively (Table III).

The Pearson Product Moment Correlation Coefficient Test, which compared the supero-inferior and medio-lateral distances of the infraspinatus tendon insertion site/footprint to the anterior extent of it, yielded corresponding $r$ values of 0.411 and 0.477 (Table III). Both correlations were accompanied by statistically significant $P$ values of 0.000 (Table III). 

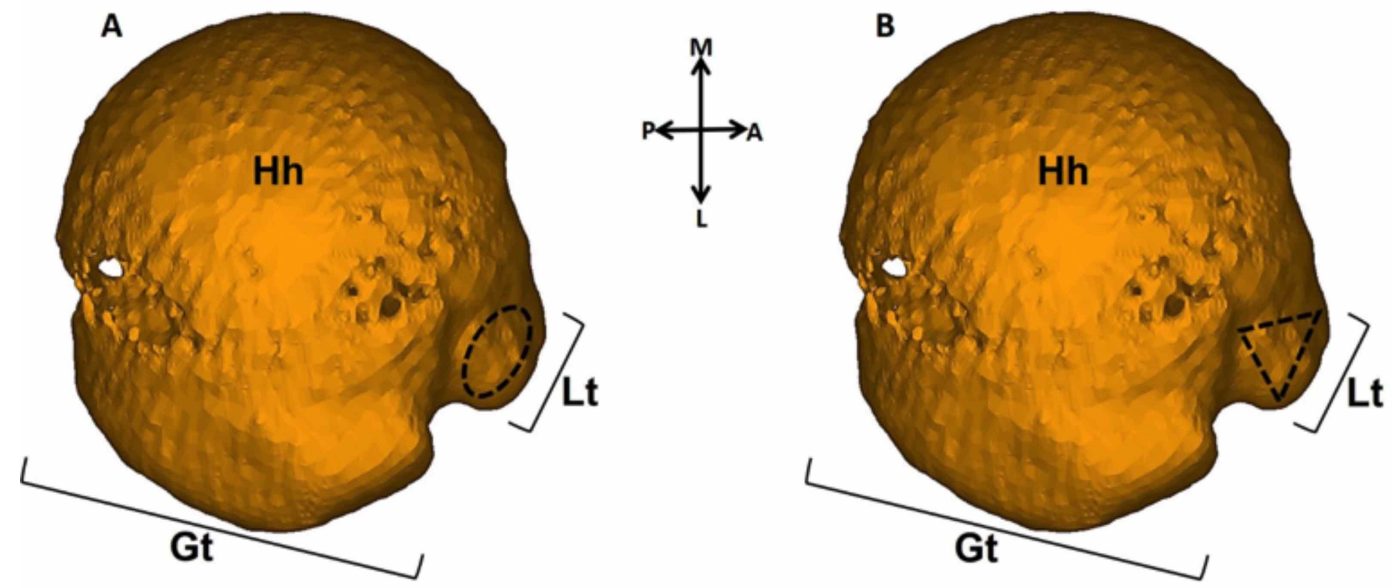

Fig. 2. Superior view of the insertional shapes of the subscapularis tendon at the lesser tubercle: A. Oval; B.Triangular. A. Anterior; Gt. Greater tubercle; Hh. Humeral head; L. Lateral; Lt. Lesser tubercle; M. Medial;P. Posterior.
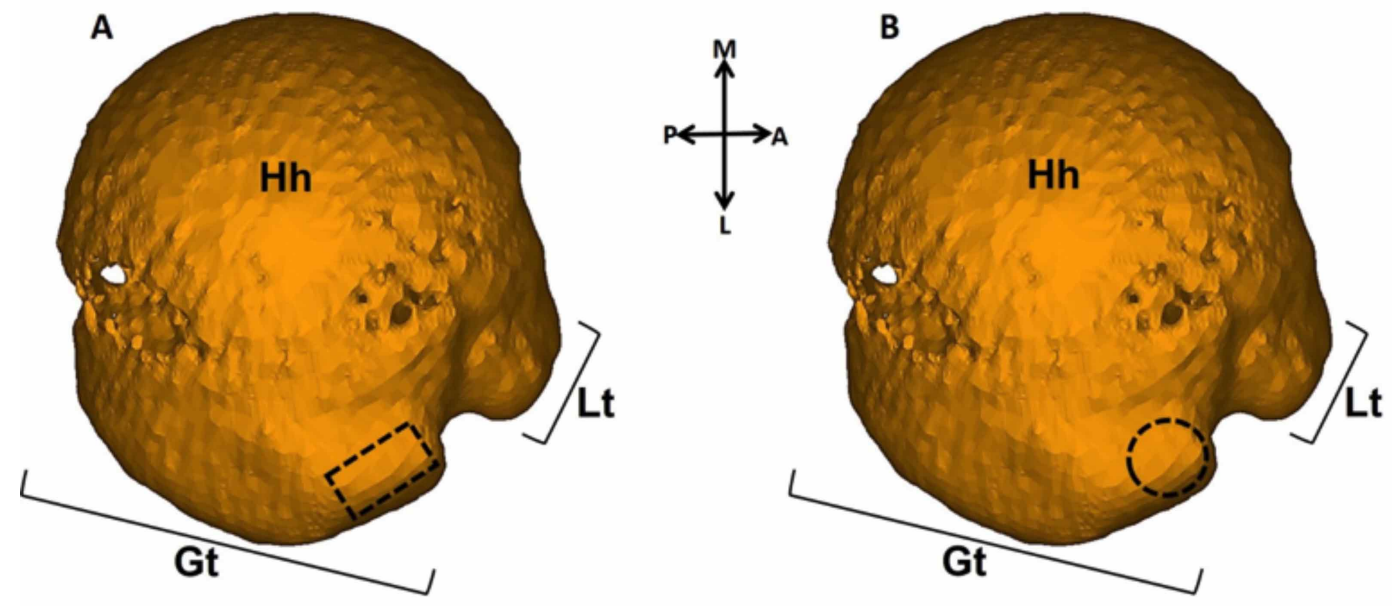

Fig. 3. Superior view of the insertional shapes of the supraspinatus tendon at the superior facet of the greater tubercle: A. Rectangular; B. Round. A. Anterior; Gt. Greater tubercle; Hh. Humeral head; L. Lateral; Lt Lesser tubercle; M. Medial; P. Posterior.
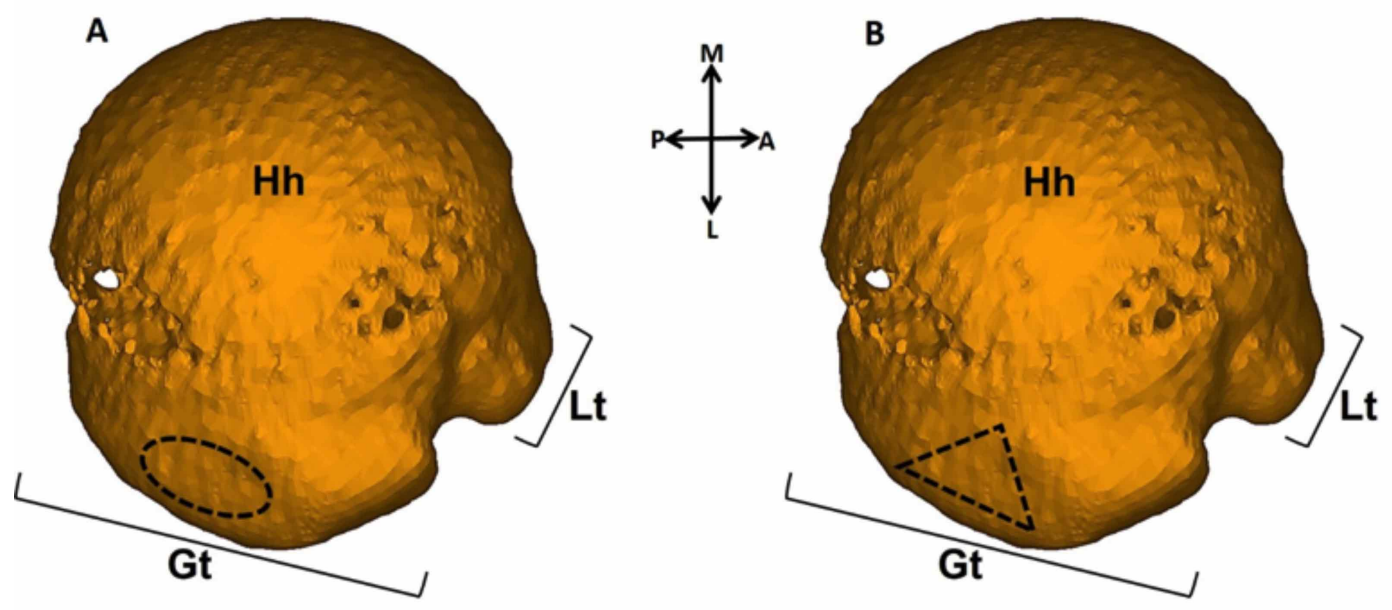

Fig. 4. Superior view of the insertional shapes of the infraspinatus tendon at the posterior facet of the greater tubercle: A. Oval; B. Triangular. A. Anterior; Gt. Greater tubercle; Hh. Humeral head; L. Lateral; Lt. Lesser tubercle; M. Medial; P. Posterior. 
Table II. Incidence of the relative shapes of the rotator cuff footprint (\%).

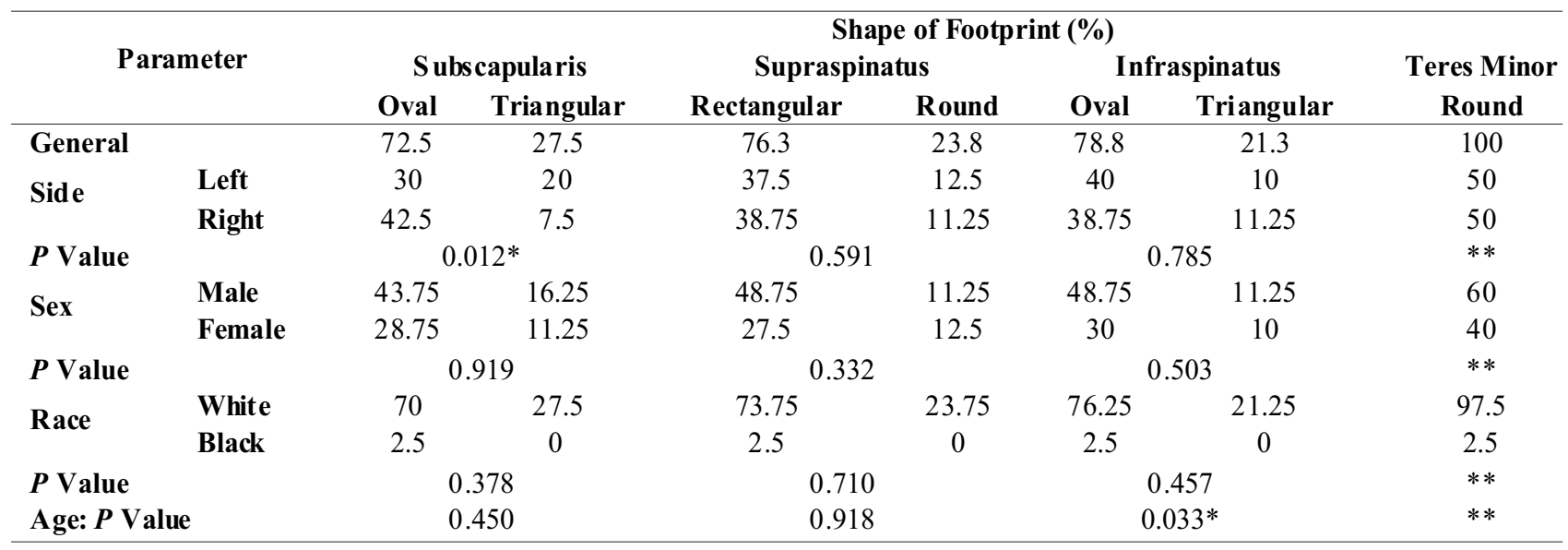

* Statistically significant P Value. **No statistics computed as the Shape of Teres minor is a constant.

Table III. Morphometry of the anterior extent of the infraspinatus muscle $(\mathrm{mm})$

\begin{tabular}{llc}
\hline \multicolumn{1}{c}{ Parameter } & Anterior extent of \\
General & Left & $10.22 \pm 3.93$ \\
Side & Right & $9.97 \pm 3.47$ \\
P Value & Male & $10.48 \pm 4.36$ \\
Sex & Female & 0.564 \\
P Value & & $10.44 \pm 3.36$ \\
Race & White & $9.90 \pm 4.69$ \\
P Value & Black & 0.554 \\
Age: P Value & & $10.28 \pm 3.96$ \\
Supero-inferior distance of & $P$ Value & $8.23 \pm 1.90$ \\
Infraspinatus & $r$ & 0.471 \\
Medio-lateral distance of & $P$ Value & 0.464 \\
Infraspinatus & $r$ & $0.000^{*}$ \\
* Statistically significant P Value & & 0.411 \\
r - Pearson Product Moment Correlation Co-efficient & $0.000^{*}$
\end{tabular}
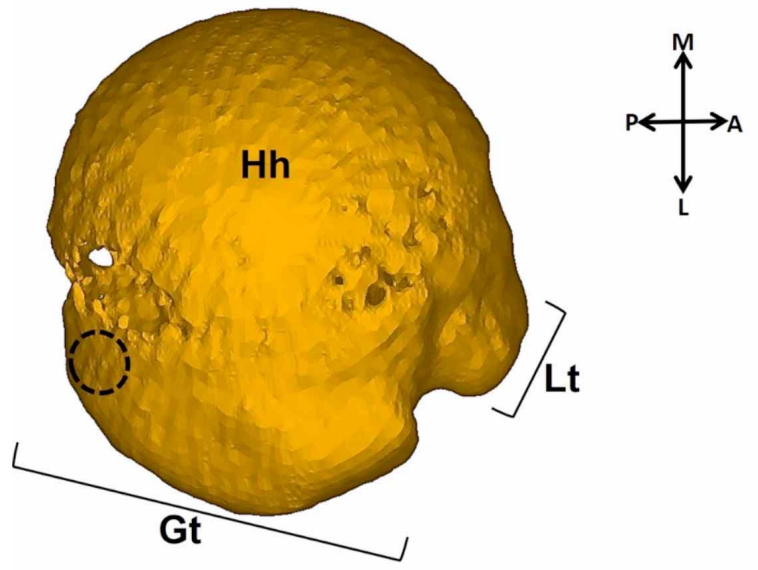

Fig. 5. Superior view of the round insertional shape of the teres minor tendon at the inferior facet of the greater tubercle: A. Anterior; Gt. Greater tubercle; Hh. Humeral head; L. Lateral; Lt. Lesser tubercle; M. Medial; P. Posterior.

\section{DISCUSSION}

The insertional anatomy of the rotator cuff, initially reported by Tierney et al.(1999), presents a measurable pattern likened to that of a horseshoe-shape that is collectively formed by the tendinous insertions of all four rotator cuff muscles (Curtis et al.,). Despite the standard anatomical reference of the rotator cuff footprint to all four tendons, many studies have delineated the footprint to the tendinous insertion sites of the supraspinatus and infraspinatus muscles only (Minagawa $e t$ al., 1998; Mochizuki et al.,; Schaeffeler et al.,; Martin Martin et al.,; Stoppino et al., 2013). While no previous study has collectively investigated the tendinous medio-lateral, tendinous supero-inferior and the supero-inferior cuff distances of the rotator cuff complex as a whole, a few reports have explored certain aspects of these parameters (Dugas et al.,; Ruotolo et al., 2004; Curtis et al.,; Mochizuki et al.,). 
Although the medio-lateral $(20.0 \mathrm{~mm})$ and supero-inferior $(40.0 \mathrm{~mm})$ distances of the subscapularis tendon insertion/footprint were only previously reported by Curtis et al. (2006), the medio-lateral distance $(20.45 \pm 4.79 \mathrm{~mm})$ of the subscapularis tendon insertion/ footprint in the present study appeared marginally larger than that of Curtis et al. (2006) (Table I). On the contrary, the supero-inferior $(22.57 \pm 3.13 \mathrm{~mm})$ distance of the subscapularis tendon insertion/footprint was lower than the $40.0 \mathrm{~mm}$ of Curtis et al., (Table I).

The medio-lateral distances of $20.14 \pm 5.38 \mathrm{~mm}$ and $19.07 \pm 4.74 \mathrm{~mm}$ recorded for the tendon insertion/ footprint regions of supraspinatus and infraspinatus, respectively, were higher than that reported by earlier studies (Dugas et al.; Ruotolo et al.,; Curtis et al.,; Mochizuki et al., 2009) (Table I). While the supero-inferior distances of the supraspinatus and infraspinatus tendon insertions/footprint regions documented by former studies (Dugas et al.,; Ruotolo et al., ; Curtis et al., 2006; Mochizuki et al.) were greater, these relevant parameters of the supraspinatus $(15.20 \pm 4.29 \mathrm{~mm})$ and infraspinatus $(19.49 \pm 5.21 \mathrm{~mm})$ in this study were correspondingly larger than those specified by Mochizuki et al., (12.6 mm) (Table I).

Moreover, both the medio-lateral $(15.33 \pm 3.75 \mathrm{~mm})$ and supero-inferior $(19.02 \pm 5.21 \mathrm{~mm})$ distances of the teres minor tendon insertion/footprint appeared larger than that of Dugas et al. but smaller than that of Curtis et al. (2006) (Table I).

With regard to the morphometry of the entire rotator cuff, Dugas et al. found the supero-inferior distance to be $37.8 \mathrm{~mm}$ which was markedly decreased to that computed in the current study $(76.28 \pm 10.57 \mathrm{~mm}$ ) (Table I). Furthermore, this study estimated a medio-lateral cuff distance of $75.18 \pm 11.41 \mathrm{~mm}$, a parameter which was not described in the literature reviewed (Table I).

The size of the morphometric parameters according to right and left side was considered. The mean superoinferior distances of the subscapularis, supraspinatus, teres minor and entire rotator cuff footprint regions were seen to be larger on the right side (Table I). The right side also presented with increased medio-lateral distances of the supraspinatus, infraspinatus and teres minor insertion/ footprint regions (Table I). Since the supero-inferior distance of the supraspinatus insertion/footprint was larger on the right side, the statistically significant $\mathrm{P}$ value (0.026) recorded for the comparison between left and right sides may indicate a generally increased supero-inferior distance in right supraspinatus tendons (Table I).
In addition to the above-mentioned general morphometric parameters, the present study also investigated these factors in light of the demographic representation of the population at hand, an analysis which was not previously conducted on the subject matter.

With the exception of the supero-inferior distance of the supraspinatus tendon insertion/footprint, the remaining supero-inferior and medio-lateral distances of the rotator cuff and its relative tendons were evidently greater in male individuals (Table I). This may be due to sex diversion in the bone-muscle relationship that is verified by the presence and release of testosterone in males which generally plays a key role in muscle-building (Lang, 2011). In addition, the levels of statistical significance reflected by the $\mathrm{P}$ values of 0.016 and 0.020 for the comparisons of the supero-inferior distance of the teres minor tendon insertion/footprint and the medio-lateral distance of the entire rotator cuff footprint, between male and female individuals, respectively may confirm that these parameters appear increased in male individuals (Table I).

The supero-inferior distances of the subscapularis, supraspinatus, infraspinatus and entire rotator cuff footprint regions were higher in White individuals. Conversely, the medio-lateral distances of the entire rotator cuff and the relative tendons were all greater in Black individuals (Table I). A larger medio-lateral distance of the teres minor tendon insertion/footprint in Black individuals was substantiated by the statistically significant $\mathrm{P}$ value of 0.022 that was recorded for the comparison of this parameter between White and Black individuals (Table I). Subsequently, in the study conducted by Wagner \& Heyward (2000), Black individuals presented with longer extremities that were relative to their heights.

Upon correlation of the supero-inferior distance of the supraspinatus tendon insertion/footprint and the entire rotator cuff insertion/footprint with their relative medio-lateral distances, the corresponding statistically significant $P$ values of 0.005 and 0.014 may suggest a directly proportional relationship between these parameters such that one distance may be used to predict the other (Table I). Furthermore, the level of significance $(\mathrm{P}$ value $=0.001)$ recorded for the comparison of the shape and the supero-inferior distance of the infraspinatus tendon insertion/footprint indicates the influence of morphology on morphometry or vice-versa and the importance of studying such parameters in conjunction with one another (Table I).

In addition to rotator cuff tendon morphometry, the shape of the insertional sites has also been documented (Dugas et al.,; Ruotolo et al.,; Curtis et al.,; Mochizuki et $a l$.$) .$ 
According to Curtis et al., the tendinous region of the subscapularis muscle appeared comma-shaped, however the current study found the subscapularis tendon to insert as oval (72.5\%) and triangular $(2.5 \%)$ patterns (Figure 2A-B, Table II). The rectangular $(76.3 \%)$ and round $(23.8 \%)$ insertion patterns of the supraspinatus tendon differed from the reports of the Curtis et al. and Mochizuki et al., who recorded trapezoidal and triangular shapes, respectively (Figure 3A$\mathrm{B}$, Table II). While teres minor insertion patterns were round in $100 \%$ of specimens, infraspinatus tendon insertions exhibited oval $(78.8 \%)$ and triangular $(21.3 \%)$ configurations (Figures 4A-B and 5, Table II). Similarly, the studies conducted by Curtis et al. and Nozaki et al. (2015) documented triangular infraspinatus insertion patterns. However, the trapezoidal infraspinatus footprint proposed by Curtis et al., was not seen in the present study. Moreover, the round teres minor footprint was in contrast to the triangular shape reported by Curtis et al.

With regard to side, triangular subscapularis, round supraspinatus and oval infraspinatus insertion sites were predominant on the left side (Table II). The right side commonly presented with oval subscapularis, rectangular supraspinatus and triangular infraspinatus footprint shapes (Table II). The round teres minor configuration was equally seen on both left and right sides (Table II). The statistically significant $\mathrm{P}$ value of 0.012 recorded for the comparison between sides and the shape of the subscapularis footprint may account for the larger prevalence of the oval shape observed on both left and right sides (Table II). Since righthandedness is reported to inhabit $90 \%$ of the world's population, it may be understood that the larger surface area depicted by the oval shape, as opposed to the smaller triangular area, is reflective of dominant handedness (Toth, 1985).

Although the round supraspinatus footprint presented with the highest incidence in female individuals (12.5\%), the remaining rotator cuff tendon insertion shapes were predominant in male individuals [Subscapularis: Oval (43.75\%), Triangular (16.25\%); Supraspinatus: Rectangular (48.75\%); Infraspinatus: Oval (48.75\%), Triangular (11.25\%); Teres minor: Round (60\%)] (Table II).

The distribution of race groups within the sample may account for the higher incidence of all insertion configurations in White individuals as they represented the majority race group [Subscapularis: Oval (70\%), Triangular (27.5\%); Supraspinatus: Rectangular (73.75\%), Round $(23.75 \%)$; Infraspinatus: Oval $(76.25 \%)$, Triangular (21.25\%); Teres minor: Round (97.5\%)] (Table II).

The level of statistical significance, indicated by the $\mathrm{P}$ value of 0.033 , for the comparison of age with the shape of the infraspinatus footprint may suggest an age-related progression in the development of different insertion configurations, such that a shape with a large surface area may decline to one resembling a smaller surface area, hence susceptibility to injury and tear. Brooks \& Faulkner (1994) explained that the relationship of muscle susceptibility with increasing age was due to underlying mechanisms. As a result, the capacity of the muscle to recover is also decreased (Brooks $\&$ Faulkner,). Furthermore, the study conducted by Martel $e t$ al. (2006) confirmed muscle hypertrophy to occur at a slower rate in older individuals than in younger ones.

Since the anterior extent of the infraspinatus tendon is considered to be a grey area in the clinical environment due to the approximate tendon coverage involved in reconstruction surgery, the present study documented a general mean value of $10.22 \pm 3.93 \mathrm{~mm}$ (Table III).

Further analysis of the anterior extension of the infraspinatus tendon led to the estimation of demographic specific data which also remain unreported in literature.

Although the infraspinatus tendon appeared to extend most anterior on the right side $(10.48 \pm 4.36 \mathrm{~mm})$, the distinct larger anterior extension in male individuals $(10.44 \pm 3.36 \mathrm{~mm})$ may be validated by the sex diversion in the bone-muscle relationship as stated by Lang (Table III). In view of the race group representation, White individuals presented with a higher mean anterior extension of $10.28 \pm 3.96 \mathrm{~mm}$ (Table III).

Despite the positive weak correlations indicated by the respective $r$ values, the comparison of the supero-inferior and medio-lateral distances of the infraspinatus tendon footprint with the anterior extent of it, presented with statistically significant $\mathrm{P}$ values (Table III). It may be postulated that the supero-inferior and medio-lateral distances may provide dimensional data required during reconstruction procedures to suture the anterior extent of the infraspinatus tendon and to obtain optimal cuff coverage (Curtis et al.,).

In view of the data obtained, this study employed direct dissection of human cadaveric material, therefore the influence of the embalming procedure was considered. While the cadaveric study of muscle allows for the observation and measurement of its structural features, even minimal amounts of formalin contained within the embalming solution have been reported to result in muscular hypertrophy (Fukunaga et al., 1997; Schramek et al., 2013). The present study was conducted on cadaveric muscle tissue subjected to standard arterial embalming via the femoral artery. The cadaveric muscle tissue was treated with embalming solution that contained $5 \%$ formalin. Due to the absence of valves in arteries, the use of the femoral artery prevented backflow with the solution 
injected between 310-410 $\mathrm{kPa}$ depending on body size. According to Cutts (1988) and Locke et al. (2010), embalming procedures performed on muscle tissue that are in isolation from the skeleton, shorten the contractile portion of muscle thus leading to shrinkage. However, as per the University of KwaZulu-Natal's embalming protocol, the procedure was done with the muscle tissue intact upon the skeleton.

Since cadaveric material is generally the source of elderly body donors, history of patient pathology and agerelated changes also present as dominant factors (Tubbs $e t$ al., 2005; Schramek et al.,). While cadaver records did not provide details of previous patient pathology, cadavers in this study ranged from middle-aged to elderly. On the contrary, the case report outlined by Tubbs $e t$ al. identified symmetric bilateral atrophy of the supraspinatus and infraspinatus muscles in a male cadaver. Although the suprascapular nerves and brachial plexus were found to be normal, histological analysis correlated this rare observation with Parsonage-Turner syndrome.

Interestingly, Martin et al. (2001)discussed the postmortem change of rigor mortis during which skeletal muscle fibres undergo a slow contraction. Through further ultrasonographic analysis, Martin et al. proposed that cadaveric skeletal muscle remains in a state of partial contraction between the in vivo extremes of relaxation and contraction. Despite the fact that Bendall (1973) found this cadaveric contraction to be negligible compared to that of living contraction, it was suggested that upon embalming skeletal muscle becomes fixed in the state of partial contraction that is typical of rigor mortis. Additional factors such as method of storage, cadaver position during storage and the long term process of degradation, may present as plausible reasons for the changes in the architecture of skeletal muscle (Martin et al.,).

\section{CONCLUSION}

In the case of full-thickness rotator cuff tears, standard dimensions of the respective tendinous insertion sites computed in the current study may assist with the reconstruction as it will ensure that adequate coverage of the cuff is achieved. Despite the variation in shape, predominant insertional patterns specific to each rotator cuff tendon were observed, viz. Subscapularis - Oval (72.5\%), Supraspinatus - Rectangular (76.3\%), Infraspinatus - Oval (78.8\%), Teres minor - Round (100\%). Since these rotator cuff insertion sites portray particular patterns, this may enhance the recognition and possible prevention of tear progression.
NAIDOO, N.; LAZARUS, L. \& SATYAPAL, K. S. La huella del manguito rotador: Un estudio en cadáver de su morfometría y morfología. Int. J. Morphol., 34(3):975-985, 2016.

RESUMEN: La capa musculotendinosa del complejo muscular del manguito rotador está formada por cuatro tendones, que se espesan y se funden con la cápsula glenohumeral subyacente a medida que se insertan en las respectivas regiones de la epífisis proximal del húmero. Se han informado varios patrones patológicos en la inserción de estos músculos que sirven como base para la reparación quirúrgica de los desgarros del manguito. La literatura previa se concentró en el estudio de macro-evaluaciones de lesiones específicas del tendón del músculo supraespinoso, por lo cual, el objetivo del presente estudio consistió en investigar los parámetros morfológicos y morfométricos macroscópicos de los cuatro tendon es del manguito rotador. Se llevó a cabo la observación de la configuración de los sitios de inserción y el cálculo relativo de la morfometría de los tendones de la región glenohumeral en una muestra de cuarenta cadáveres adultos $(\mathrm{n}=80)$ los que fueron disecados bilateralmente. El análisis estadístico también refleja la representación demográfica de la muestra: Edad: 74,83 \pm 12,92 años de edad; Género: 24 hombres, 16 mujeres; Raza: 38 Blan$\cos , 2$ Negros. Las distancias medias supero-inferior y medio-lateral se registraron específicamente en todo el manguito rotador y en cada sitio de inserción tendinosa de la siguiente manera: i) M. subescapular: 22.57 $\pm 3.13 \mathrm{~mm}, 20.45 \pm 4.79 \mathrm{~mm}$; ii) M. supraespinoso: $15.20 \pm 4.29 \mathrm{~mm}$, $20,14 \pm 5.38 \mathrm{~mm}$; iii) M. infraespinoso: $19.49 \pm 5.21 \mathrm{~mm}, 19,07 \pm 4.74$ $\mathrm{mm}$; iv) M. redondo menor: $19.02 \pm 5.21 \mathrm{~mm}, 15,33 \pm 3,75 \mathrm{~mm}$; v) manguito rotador completo: $76.28 \pm 10.57 \mathrm{~mm}, 75,18 \pm 11.41 \mathrm{~mm}$. Aunque existe una variación en la configuración de la inserción, se identificaron las formas predominantes: M. subescapular - ovalado (72,5 $\%)$, M. supraespinoso - rectangular (76,3\%), M. infraespinoso - ovalado $(78,8 \%)$, M. redondo menor - redonda (100 \%). En vista de los valores p estadísticamente significativos, puede postularse que el conocimiento de las distancias supero-inferior y medio-laterales puede proporcionar datos dimensionales requeridos para obtener una cobertura óptima del manguito durante los procedimientos de reconstrucción. Además, la variación en los patrones de inserción puede indicar la progresión de desgarros de los tendones del manguito..

PALABRAS CLAVE: Manguito rotador; Huella; Inserción; Morfología; Morfometría.

\section{REFERENCES}

Armfield, D. R.; Stickle, R. L.; Robertson, D. D.; Towers, J. D. \& Debski, R. E. Biomechanical basis of common shoulder problems. Sem. Musculoskelet. Radiol., 7(1):5-18, 2003.

Bendall, J. R. The structure and function of Muscles II: Postmortem changes in muscle. Bourne G ed. London, Academic Press, 1973.

Brooks, S. V. \& Faulkner, J. A. Skeletal muscle weakness in old age: underlying mechanisms. Med. Sci. Sports Exerc., 26(4):432-9, 1994.

Cadet, E. R.; Vorys, G. C.; Rahman, R.; Park, S. H.; Gardner, T. R.; Lee, F. Y.; Levine, W. N.; Bigliani, L. U. \& Ahmad, C. S. Improving bone density at the rotator cuff footprint increases supraspinatus tendon failure stress in a rat model. J. Orthop. Res., 28(3):308-14, 2010. 
Curtis, A. S.; Burbank, K. M.; Tierney, J. J.; Scheller, A. D. \& Curran, A. R. The insertional footprint of the rotator cuff: an anatomic study. Arthroscopy, 22(6):609.e1, 2006.

Cutts, A. Shrinkage of muscle fibres during the fixation of cadaveric tissue. J. Anat., 160:75-8, 1988

Dugas, J. R.; Campbell, D. A.; Warren, R. F.; Robie, B. H. \& Millett, P. J. Anatomy and dimensions of rotator cuff insertions. J. Shoulder Elbow Surg., 11(5):498-503, 2002.

Fukunaga, T.; Ichinose, Y.; Ito, M.; Kawakami, Y. \& Fukashiro, S. Determination of fascicle length and pennation in a contracting human muscle in vivo. J. Appl. Physiol. (1985), 82(1):354-8, 1997.

Jurch, S. E. Clinical Massage Therapy: Assessment of Treatment of Orthopaedic Conditions. New York, McGraw-Hill Higher Education, 2009.

Lang, T. F. The bone-muscle relationship in men and women. $J$. Osteoporos., 2011:702735, 2011.

Locke, J.; Baird, S. A. \& Frankis, J. Preliminary observations of muscle fibre cross sectional area of flexor digitorum brevis in cadaver feet with and without claw toes. J. Foot Ankle Res., 3:32, 2010.

Martel, G. F.; Roth, S. M.; Ivey, F. M.; Lemmer, J. T.; Tracy, B. L.; Hurlburt, D. E.; Metter, E. J.; Hurley, B. F. \& Rogers, M. A. Age and sex affect human muscle fibre adaptations to heavy-resistance strength training. Exp. Physiol., 91(2):457-64, 2006.

Martin, D. C.; Medri, M. K.; Chow, R. S.; Oxorn, V.; Leekam, R. N.; Agur, A. M. \& McKee, N. H. Comparing human skeletal muscle architectural parameters of cadavers with in vivo ultrasonographic measurements. J. Anat., 199(Pt. 4):429-34, 2001.

Martin Martin, S.; Rapariz, J. M.; Pico, M.; Garcia, M. A. \& Martinez, C. Tears at the rotator cuff footprints: imaging characteristics on MRI and ultrasound, evolutions and clinical significance. E.S.R., $1-14,2012$

Minagawa, H.; Itoi, E.; Konno, N.; Kido, T.; Sano, A.; Urayama, M. \& Sato, K. Humeral attachment of the supraspinatus and infraspinatus tendons: an anatomic study. Arthroscopy, 14(3):3026, 1998.

Mochizuki, T.; Sugaya, H.; Uomizu, M.; Maeda, K.; Matsuki, K.; Sekiya, I.; Muneta, T. \& Akita, K. Humeral insertion of the supraspinatus and infraspinatus. New anatomical findings regarding the footprint of the rotator cuff. Surgical technique. $J$. Bone Joint Surg. Am., 91 Suppl. 2 Pt. 1:1-7, 2009.

Muscolino, J. E. The Muscular System Manual: The Skeletal Muscles of the Human Body. $3^{\text {rd }}$ Ed. Mosby Inc., Missouri, 2010.

Nozaki, T.; Nimura, A.; Fujishiro, H.; Mochizuki, T.; Yamaguchi, K.; Kato, R.; Sugaya, H. \& Akita, K. The anatomic relationship between the morphology of the greater tubercle of the humerus and the insertion of the infraspinatus tendon. J. Shoulder Elbow Surg., 24(4):555-60, 2015.

Rockwood, C. A.; Frederick, J. R.; Matsen, A.; Wirth, M. A. \& Steven, B. The Shoulder. USA, Elsevier, 2004.
Ruotolo, C.; Fow, J. E. \& Nottage, W. M. The supraspinatus footprint: an anatomic study of the supraspinatus insertion. Arthroscopy, 20(3):246-9, 2004.

Schaeffeler, C.; Mueller, D.; Kirchhoff, C.; Wolf, P.; Rummeny, E. J. \& Woertler, K. Tears at the rotator cuff footprint: prevalence and imaging characteristics in 305 MR arthrograms of the shoulder. Eur. Radiol., 21(7):1477-84, 2011.

Schramek, G. G.; Stoevesandt, D.; Reising, A.; Kielstein, J. T.; Hiss, M. \& Kielstein, H. Imaging in anatomy: a comparison of imaging techniques in embalmed human cadavers. B. M. C. Med. Educ., 13:143, 2013

Sinnatamby, C. S. Last's Anatomy: Regional \& Applied. $11^{\text {th }}$ Ed. Churchill. New York, Livingstone, 2006.

Standring, S. Gray's Anatomy: The Anatomical Basis of Clinical Practice. Spain, Elsevier Ltd., 2008.

Stoppino, L. P.; Ciuffreda, P.; Rossi, M.; Lelario, M.; Bristogiannis, C.; Vinci, R.; Genovese, E. A. \& Macarini, L. Lesions of the rotator cuff footprint: diagnostic performance of MR arthrography compared with arthroscopy. Musculoskelet. Surg., 97 Suppl. 2:S197$202,2013$.

Tierney, J. J.; Curtis, A. S.; Kowalik, D. L. \& Scheller, A. D. The footprint of the rotator cuff. Arthroscopy., 15: 556-557, 1999.

Toth, N. Archaeological evidence for preferential right-handedness in the lower and middle Pleistocene, and its possible implication. $J$. Hum. Evol., 14: 607-614, 1985.

Tubbs, R. S.; Salter, E. G. \& Oakes, W. J. Severe bilateral atrophy of the spinati muscles in a cadaver. Folia Morphol. (Warsz.), 64(3):224-5, 2005.

Wagner, D. R. \& Heyward, V. H. Measures of body composition in blacks and whites: a comparative review. Am. J. Clin. Nutr., 71(6):1392-1402, 2000.

Correspondence to:

Professor KS Satyapal

Department of Clinical Anatomy

School of Laboratory Medicine and Medical Sciences

College of Health Sciences

University of KwaZulu-Natal

Private Bag X54001

Durban

4000

SOUTH AFRICA

E-mail address:satyapalk@ukzn.ac.za

Recibido : 05-04-2016

Aceptado: 04-07-2016 